\title{
Teachers' Perceptions on Using Augmented Reality for Language Learning in Primary Years Programme (PYP) Education
}

\author{
https://doi.org/10.3991/ijet.v15i12.13499 \\ Ahmed Ashely-Welbeck \\ University of Roehampton (London) Online, London, United Kingdom \\ Dimitrios Vlachopoulos $(\bowtie)$ \\ Amsterdam University of Applied Sciences, Amsterdam, Netherlands \\ d.v.vlachopoulos@hva.nl
}

\begin{abstract}
Augmented Reality (AR) is a relatively new technology and is increasingly being posited as an educational game-changer, particularly - but not exclusively - in language learning. On a scale where the virtual and real world sit at opposite ends of the spectrum, AR sits in-between, combining real world elements with virtual overlays. Research suggests that an obstacle to English language learning in countries where English is not the first language (EFL) is a "...lack of authentic situations outside of the classroom for practising English communication skills" [1]. AR technology, by combining elements of real-life and virtual content could potentially overcome some of these limitations. However, as with all technologies, the use of AR in the classroom is not only confined to the learner, but also largely dependent on the willingness and skills of teachers to utilise it effectively. This study hopes to shed some light on the possible uses, benefits, and challenges that AR may present to the field of EFL learning in an Egyptian International Baccalaureate (IB) school.
\end{abstract}

Keywords-Augmented Reality, language learning, International Baccalaureate, Primary Years Programme.

\section{Introduction}

Augmented Reality (AR) is a relatively new technology and is increasingly being posited as an educational game-changer, particularly - but not exclusively - in language learning [2]. On a scale where the virtual and real world sit at opposite ends of the spectrum, AR sits in-between, combining real world elements with virtual overlays [3]. In Egypt, the emphasis on learning to communicate effectively in English begins in the first year of schooling [4]. Egyptian society in general has for some time viewed the acquisition of the English language as an upward trend in social mobility. Attitudes and motivations towards the early learning of English and upward social, and economic mobility are intrinsically linked [5]. However, there are some identified obstacles to learning and teaching English in (EFL) countries which 
inevitably hinder progress. Of these obstacles, vocabulary acquisition and retention is possibly the most significant challenge that second language learners (L2) face [6]. One of the main issues debated in available literature is whether L2 language acquisition is more effective when words are inferred, or given outright. Inferred would suggest a more constructivist approach to vocabulary acquisition [7], where teachers afford opportunities for learners to build upon previous knowledge and experience in contextualizing the meaning of a new word. Research suggests that another such obstacle is a "...lack of authentic situations outside of the classroom for practising English communication skills" [1] and shows that leaners who spend extended time in the community of a target language, have a better chance of mastery over the language [8]. The cost, time, and travel implications of affording learners access to such an experience is a significant consideration. AR technology, by combining elements of real-life and virtual content could potentially overcome some of these limitations $[9,10]$. However, as with all technologies, the use of AR in the classroom is not only confined to the learner, but also largely dependent on the willingness and skills of teachers to utilise it effectively. This study hopes to shed some light on the possible uses, benefits, and challenges that AR may present to the field of EFL learning in an Egyptian International Baccalaureate (IB) school. The significance of the IB in this context is due to the constructivist pedagogical methods it posits for language learning proficiency throughout its three stage learning programmes: primary, middle, and diploma [11]. The research questions of the study are as follows:

- Q1. What skills and knowledge do PYP teachers need to support the use of AR in their classrooms?

- Q2. What are the challenges of using AR in PYP learning, as perceived by teachers?

- Q3. What are the opportunities for using AR in PYP language education?

\section{$2 \quad$ Literature Review}

\subsection{Introduction}

AR is but a chapter in the story of classroom technologies. It has not been widely used in the classroom to date, thus there is scant literature to inform teachers about it $[12,13,14]$. To understand the volume of research in the field of AR for primary language learning, and of teachers' perceptions towards it, one must first revisit the chronology of individual published works of technology in the classroom as a whole. It is only by piecing together the fragmented, empirical works, that one is able to gain a picture of what the challenges, benefits, and discussions are surrounding it. Thus, this literature review will present an overview of AR in education (history, foundational theories, and motivation) and will present the perceptions regarding classroom technologies - an exploration into the causes and reasons for teachers' beliefs in classroom technology integration. 


\subsection{Augmented reality in education: A brief history}

Tom Caudell, a Boeing systems researcher, is believed to have coined the term "Augmented Reality" back in 1990 [15]. Early discussions on the use of AR, such as the seminal works of Azuma [16], focused primarily on the benefits of the technology as a means to enhance training in commercial and manufacturing fields such as entertainment, engineering, medicine, and robotics. There was no mention of language learning, or even education as a whole. The goal posited in Azuma's much celebrated works, 'A survey of Augmented Reality' was three-fold: to culminate the existing works of the time, to help readers to build AR systems, and to uncover some of the limitations in the hardware and software of the mid-to-late 90s. This included alignment issues with virtual and real-life objects, of which the resulting lags and delays inevitably hindered the realism of the experience. The user experience was comparatively ignored in favour of the discussion on the technology itself, and there was little to no mention of the academic affordances and/or limitations.

The majority of literature found to focus on the academic use of AR, appears post c2000. One such early survey by Dunleavy et al. [17] demonstrated how AR could enhance learning by simulating environments that would have otherwise been unattainable in a traditional classroom. For example, Shelton \& Hedley [18] described in their paper, the benefits afforded to undergraduates studying an earth-sun relationship. Analysis of the study revealed that the 3D nature of the activities the students were engaged in allowed them greater "...cognitive access to complex visualisations compared to conventional desktops" [19]. Early studies in AR which focused on younger learners include an often cited study on the Magicbook by Billinghurst et al. [20], which was designed to enhance the reading experience by overlaying 3D virtual characters over the original book pages. Although designed for children, the project was never actually used on primary stage children. Studies on the effects of AR for younger language learners are much more recent and less in volume, most of which have been exploratory, and relatively short-term with small sample sizes [12].

\subsection{Situated cognition}

Similarly, Santos et al. [21] argue the case for situated cognition as a theoretical base for AR language learning. Situated cognition posits that learning cannot be separated from the context that developed the content and thus any vocabulary presented in an AR environment is "...learned in the context of its use thus facilitating knowledge transfer" [21] allowing learners of new foreign words to immediately place that knowledge atop previously known objects or scenes to construct new understandings. This is significant to a study within an IB context due to the constructivist, inquiry-based basis of the IB and PYP learning methodology [22]. Vooren et al. [23], in a study of additional language learning in the PYP describes the dilemma faced by teachers in balancing the ideals of self-directed inquiry as preferred by the IB, and traditional teaching techniques of acquiring new words. In this study 
four major challenges are cited: teacher resistance to inquiry, limited instruction time, limited language proficiency, and limited resources.

\subsection{Cognitive load}

The theory of cognitive load suggests a limit to the human ability to accommodate information into working memory [24]. There are generally three types of load identified by the literature: intrinsic (difficulty of materials), extraneous (ineffective use of material), and germane (mental effort exerted by learners) [25]. If overloaded, the capacity to take in information becomes hampered, thus having a negative impact on learning performance [24]. Its significance in the discussion of AR for the classroom is substantial. Chu's 2014 [26] study of the negative effects of mobile learning on students concluded that the mix of real-world and scenarios and additional data from mobile devices "...obtained unfavourable learning achievements" [26] due to high cognitive load. The study, which employed an experimental approach methodology, was able to prove this using the t-test results of a formative assessment conducted by control and experimental groups. However, the study failed to empirically state the type of cognitive load that was the root of the problem. This is significant because an extraneous load could potentially suggest that the inappropriate application of the formative assessment offered to the test participants - and/or the improper use of materials - contributed to the mental load, forcing an increase in germane cognitive effort applied by students. In the Cheng study which used an AR reading book to measure the effects of cognitive load on young learners, results of a quantitative survey “...suggested perceptions of low level cognitive load on students" [25] whilst simultaneously showing an increase in motivation and positive attitude to the learning process. Significant to the discussion was the exploration of the role of motivation, and its effect on the cognitive load.

\subsection{Motivation}

Motivation is a significant factor in language learning performance [45]. All research into AR that has focused on motivation as a variable, has concluded that there is a significant increase in motivation amongst learners [27]. Solak \& Cakir's 2015 study of AR use in the language classroom [28] used a Turkish version of the Material Motivational Survey to determine that AR increased engagement and motivated learners through the use of animations, videos, and sound in a 3D environment which could be viewed from all angles. This, they suggested, suited younger "digital natives" [29] who are more familiar with handling such devices and thus greatly inspired by technology use in the classroom [28]. Similarly, in a study of AR to promote learning, Ozdamli \& Hursen, concluded that enhanced enjoyment and increased motivation were the highest factors recorded [30].

Studies suggest this heightened motivation could be a significant benefit in the language learning classroom. In a study which focused on improving English speaking proficiency in Saudi public schools, Alharbi [1] explains how several factors decreased motivation. One of which was the teachers' inability or reluctance to 
explain more complex points in English, instead reverting to the primary spoken language. The answer to this, according to Alharbi [1] was more self-determined, inquiry-based learning for students, something which AR applications are posited to promote. Cabero-Almenara \& Osuna [31] posit that AR fulfils the self-determination and inquiry factors of learning because students actively participate in "...making their own discoveries through the establishment of a connection between the information that is presented to them by means of different channels..." instead of listening only [31]. Other examples exist of studies that have incorporated nativespeaking elements into AR software designed for language learning. The software used in the Santos et al. [21] study of AR use for vocabulary learning was designed using a combination of text, images and native-speaking audio clips, thus constituting a multimedia learning theory and resulting in better retention, as well as "...reducing cognitive load, improving attention, and increasing satisfaction" [21]. However, results differed in the $\mathrm{Li}$ et al. [32] pilot study, which explored AR's ability to increase motivation to learn English amongst Chinese college students. Li et al. found that motivation waned significantly during the use of the software, and researchers attributed three reasons for this. Firstly, they considered the pre-made AR application content to be too far removed from the interests of their participants. Secondly, participants struggled to meet learning goals, and lastly, lags in the software's ability to recognise triggers distracted attention away from learning. All three stated issues could stem from poor application development. The Santos et al. [21] study used software developed exclusively for the study, yet its findings and did not express similar challenges. This is significant to this author's study as the software used here is also pre-made and thus, could present unforeseen motivational challenges amongst students which could inadvertently alter teacher perceptions towards it.

\subsection{Teachers' perceptions on technology integration}

Generally, a person's negative experiences with an issue, can influence their beliefs on that issue significantly [33]. The same applies to teachers' use of technology in their practice. More than half the teachers who have access to computers in the classroom use them for administrative purposes only [34]. The pedagogical theories a teacher adheres to also play a significant role. Teachers select technologies based on their pedagogical beliefs about teaching and learning [35]. In a seminal study of teacher perceptions toward technology integration, Niederhauser \& Stoddart [36] claim that teachers who follow a behaviourist, teacher centred learning methodology are more likely to view technology as a tool to reinforce skills, to practice and memorise skills and information, or for rewards. In contrast, those that adhere to a more constructivist, inquiry-based pedagogical approach to learning are, more likely to use software in an open-ended way in the classroom.

However, even teachers who have positive perceptions about technology in education can reach a barrier which hinders its integration [33] and those with little access to technology focused professional development are less likely to use it in the classroom. It is imperative that both teachers and students have at least a basic knowledge of a technology before using it for effective learning [34]. Although this 
requires teacher training, according to Tondeur et al. [37] singe workshops are not enough. In a study focused on the relationship between teachers' pedagogical beliefs and use of technology in the classroom, it was concluded that professional development aimed at increasing familiarity with technology integration showed lean results. Instead, the study suggests that long term, ongoing professional development, possibly from a pre-service stage, was necessary for successful and meaningful integration.

\section{$3 \quad$ Research Methodology}

Benbasat, Goldstein \& Mead [38], in a seminal paper on case research strategy in studies of information systems, suggest the researchers consider the following questions:

1. "Can the phenomenon of interest be studied outside its natural setting?

2. Must the study focus on contemporary events?

3. Is control or manipulation of subjects or events necessary?

4. Does the phenomenon of interest enjoy an established theoretical base?"

The answers to the above questions conclude that the case study approach is indeed well-suited for this study. Firstly, due to the nature of the subject, exploratory research into emerging, contemporary technologies such as AR use in the classroom, cannot be effectively studied outside of its natural environment [39]. Secondly, there is no justification or need for manipulation or control of the teacher participants in this case. The perceptions of the teachers are to be observed, recorded, and analysed regardless of their nature. As the nature of the study required that a theory be formed from the data, all data collected were relevant and there were no right or wrong answers. Lastly, due to the fact that AR use in the classroom is relatively new, there is little in terms of literature to inform about teachers' perceptions to it [12] and even less literature pertaining to PYP schools using it for language learning. Thus, there is not a strong, and established theoretical base [38]. Following purposive sampling, eight PYP homeroom teachers from the same IB school were selected to be interviewed for the study, through semi-structured face-to-face interviews.

\section{$4 \quad$ Results}

The findings are presented in order of their relevance to the research questions. The classifications and relevancy to questions can be seen below (figure 1). Results of the study provided answers to all three study questions, albeit to varying degrees, and holistically showed that teacher participants perceived the augmented reality application to be appropriate to the PYP learning methodology and to a somewhat lesser degree, language learning. Teacher attitudes toward technology were found to be significant to ensure a successful implementation in the classroom, and results were also, for the most part, consistent with the existing literature in the field with 
regards to enhanced student motivation, as perceived by the participating teachers and also the engagement benefits of gamification. Coding revealed 322 individual codes culminating in four major classifications: teachers' beliefs and attitudes, training and skills, challenges to the technology, and relevance to learning. Within each of these classifications were nested the multiple themes which emerged as relevant to the research questions.
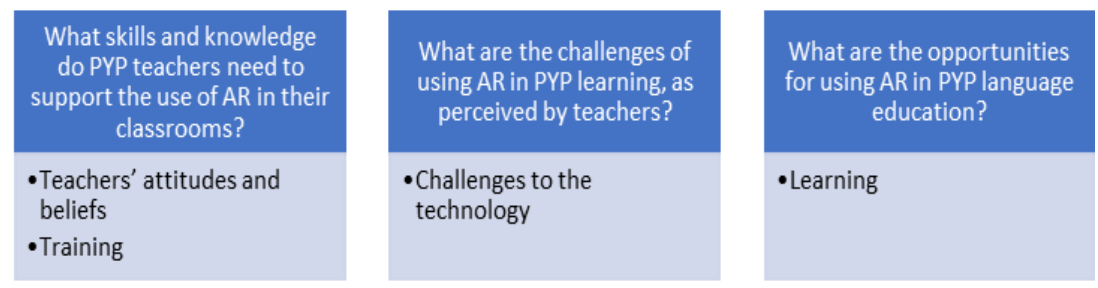

Fig. 1. Identification of the afore-mentioned classifications and their relevance to the research questions, shows 2 of the 4 themes as relevant to Q1 with the remaining themes equally divided between the remaining 2 questions.

\subsection{Findings relevant to the skills and knowledge needed by PYP teachers to support the use of $A R$ in the classroom.}

By far the largest aggregated classification relevant to Q1 was that of 'teachers' attitudes and beliefs' toward technology, containing $49 \%$ of the recorded reference codes for the entire study. Within 'beliefs and attitudes' two nested themes emerged: personal use of technology and teacher familiarity with technology, making up $32 \%$ of the classification. The study found that $100 \%$ of the teacher participants considered themselves to be technically savvy, using some form of mobile or desktop device every day. The most common uses included social media, GPS, and news applications. Analysis of the training classification's nested themes overwhelmingly suggested that teachers perceived the application to be "easy" and "comfortable to use". Despite all 8 teachers reporting that no technical knowledge was required prior to, and in order to use the application, there were explicit indications of a need to familiarize themselves with the application's functions for more effective use. Teachers 1 and 8 made reference to the time taken to familiarize themselves with the application before using it with their respective students; 7 to 8 minutes, and 10 to 15 minutes respectively.

The result of an NVivo text search query of 'training' under the classification of the same name revealed references explicitly indicating the reason for the perception of ease: familiarity with the technology being used (figure 2). 


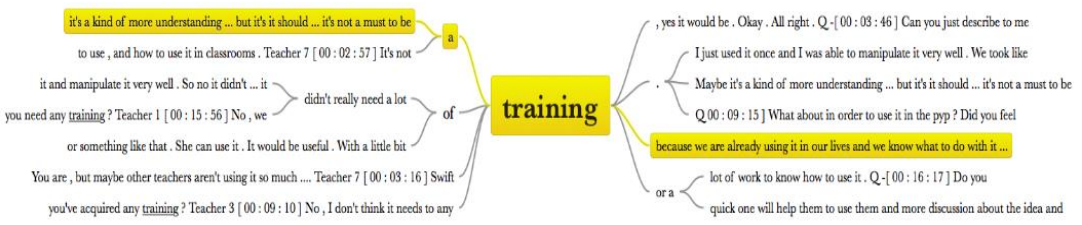

Fig. 2. NVivo text search query of 'training' under the classification of the same name

Further investigation by means of a matrix coding query revealed a significant link between the lack of a need for training, previous knowledge and/or familiarity with technology, and challenges faced when using the AR application. Teachers 4 and 6 responded most frequently under the themes of 'technology familiarity' as well as 'personal use of technology' with the former containing at least twice as many references as the remaining participants. Subsequently, the same teachers were also referenced more frequently as having solved the technical issues that they identified during the use of the AR application (figure 3).

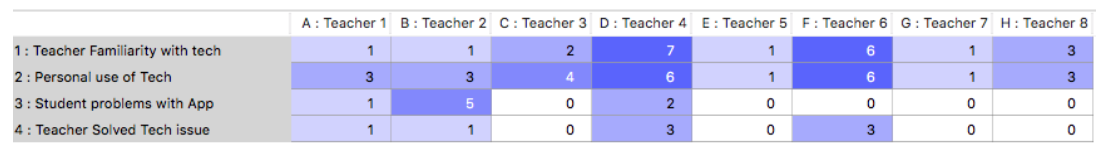

Fig. 3. NVivo query displaying the themes entered and the corresponding number of references offered by the participating teachers.

An example can be seen in a reference made by Teacher 8 (figure 4). A description of the inability of teachers feeling "comfortable" using the new technology is directly linked to familiarity with technology in general. Despite the fact that Teacher 8 was speaking about what has been experienced by watching others, it appears to be a confirmation of her perception towards the general technical skills required.

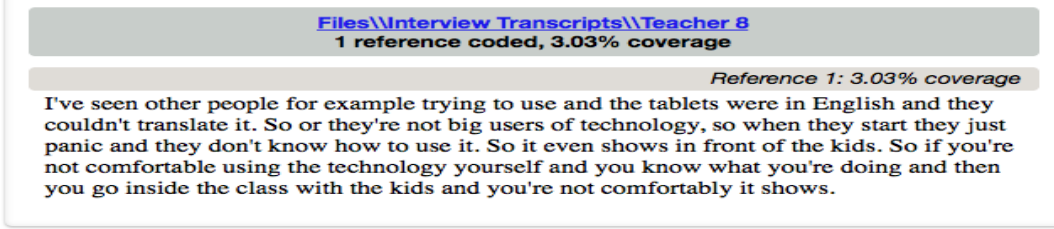

Fig. 4. Reference made by Teacher 8, explicitly indicating lack of familiarity with technology as one of the reasons teachers may struggle to implement the technology successfully in the classroom.

Triangulated reinforcement of the theory came in the form of the current literature where it is widely posited that lack of familiarity or negative experiences with technology, hinders teachers' ability to use technology effectively in the classroom and could adversely prevent frequent or recurring use [33]. To further test the theory 
an NVivo matrix coding query was run which compared the themes of familiarity, negative attitudes or cautions expressed by teachers, and lastly, the negative perceptions of students' attitudes to technology. The results found that the participants who most frequently expressed caution towards general technology use, also recorded greater references to perceived negative effects on students' use of the AR application (figure 5). Cautious and/or negative perceptions centered around limiting the time children spent using technological devices ( 5 references), risks to children's health (2 references), and a perceived negative effect on the social lives of children (2 references). In addition, those teachers also showed higher levels of familiarity with technology, a factor which is again supported by the literature which suggests that even teachers who hold positive perceptions about technology in general can harbor certain negativities which hinder its integration [33].

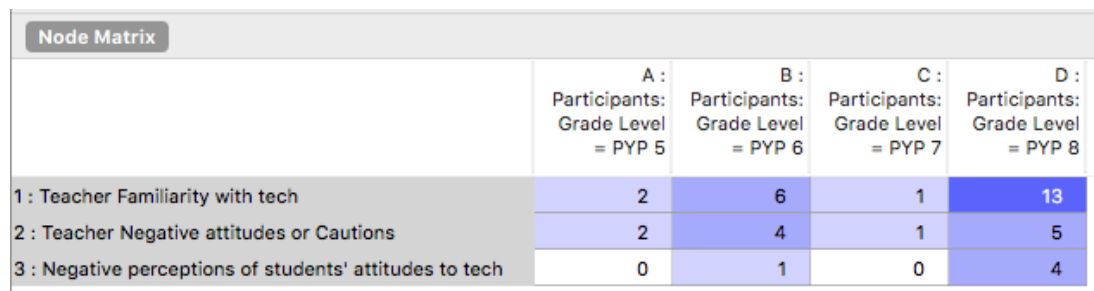

Fig. 5. NVivo query displaying the themes entered and the corresponding number of references offered by the participating teachers.

Despite the perceived negatives, a number of references were made about the benefits of technology use over non-use by 7 of the 8 teachers. Coded as 'benefits of tech over non-tech' this identified theme was considered relevant to the 'learning' as well as the 'beliefs' classifications and resulted in an average of $4 \%$ in terms of the coverage of references of participants (figure 6). 


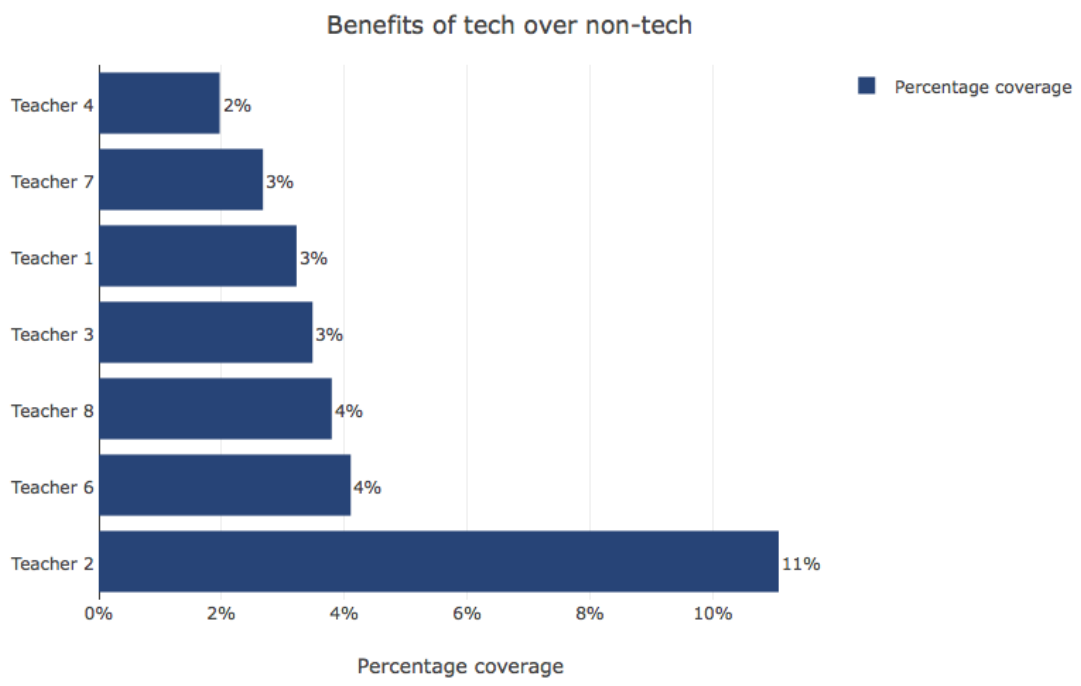

Fig. 6. NVivo display of theme of benefits of technology over non-technology use in the classroom and corresponding number of references offered by the participating teachers.

\subsection{Findings relevant to the challenges of using AR in PYP learning, as perceived by teachers.}

Although very few challenges were identified, three prominent themes emerged: 'technical issues', which involved failures of the technology (hardware or software); 'student related problems' encountered during the use of the AR application; and finally, 'needed improvements' for the AR application to be more effective for learning. With the link between technical issues and teacher familiarity identified, the research turned its focus on the findings within the themes of student related problems, and what teachers perceived as improvements needed. An analysis of the codes revealed two prominent references: issues with sound/volume levels of the application audio, and issues with students unable to hold the tablet to initiate the AR graphics whilst recording the information it revealed.

\subsection{Findings relevant to the opportunities for using the AR app for language learning as perceived by teachers.}

This study found that whilst participating teachers perceived the app as possible and beneficial for language learning, far more emphasis was put on its appropriateness to the wider learning method of the PYP. An analysis of the classification titled 'Learning' revealed a hierarchy of coded themes in which 'language use' did not prove the most prominent with just under $21 \%$ of the references (figure 7). As an aggregated theme, 'PYP' (which culminated in 5 subthemes) contained $41 \%$ of the 100 references made to learning in the study. As the 
study participants taught in a range of grade levels, an NVivo analysis to chart references to language use based on a grade level was conducted; however, the selected criteria produced no discernable, striking, or obvious patterns that could aid in answering question 3 or relate to the other previous questions. Despite this, readings of the references and a manual analysis of the sub-themes told a story within which several significant findings for language learning did emerge. These findings are presented below under the headings of vocabulary, pronunciation, and grammar and translation.

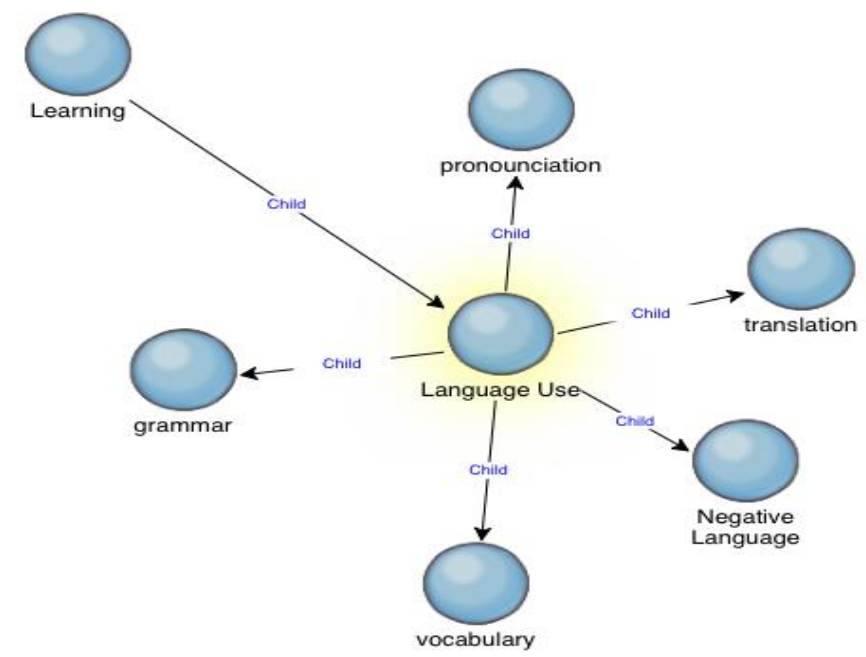

Fig. 7. NVivo query displaying the themes under the classification of learning and the corresponding number of references offered by the participating teachers.

Vocabulary: Five of the 8 teachers perceived opportunities for enhancing vocabulary. Of these, the highest number of coded references for any one participant was nine. $86 \%$ of the references to vocabulary referred to the audio feature of the World Map where the names of continents, countries, wildlife, and the names of heritage sites previously unknown were repeated by students suggesting that learning of new words was taking place. An example summary by teacher 2 suggests that student repetition of the words as heard in the AR application audio aided memorization and increased vocabulary (figure 8). 


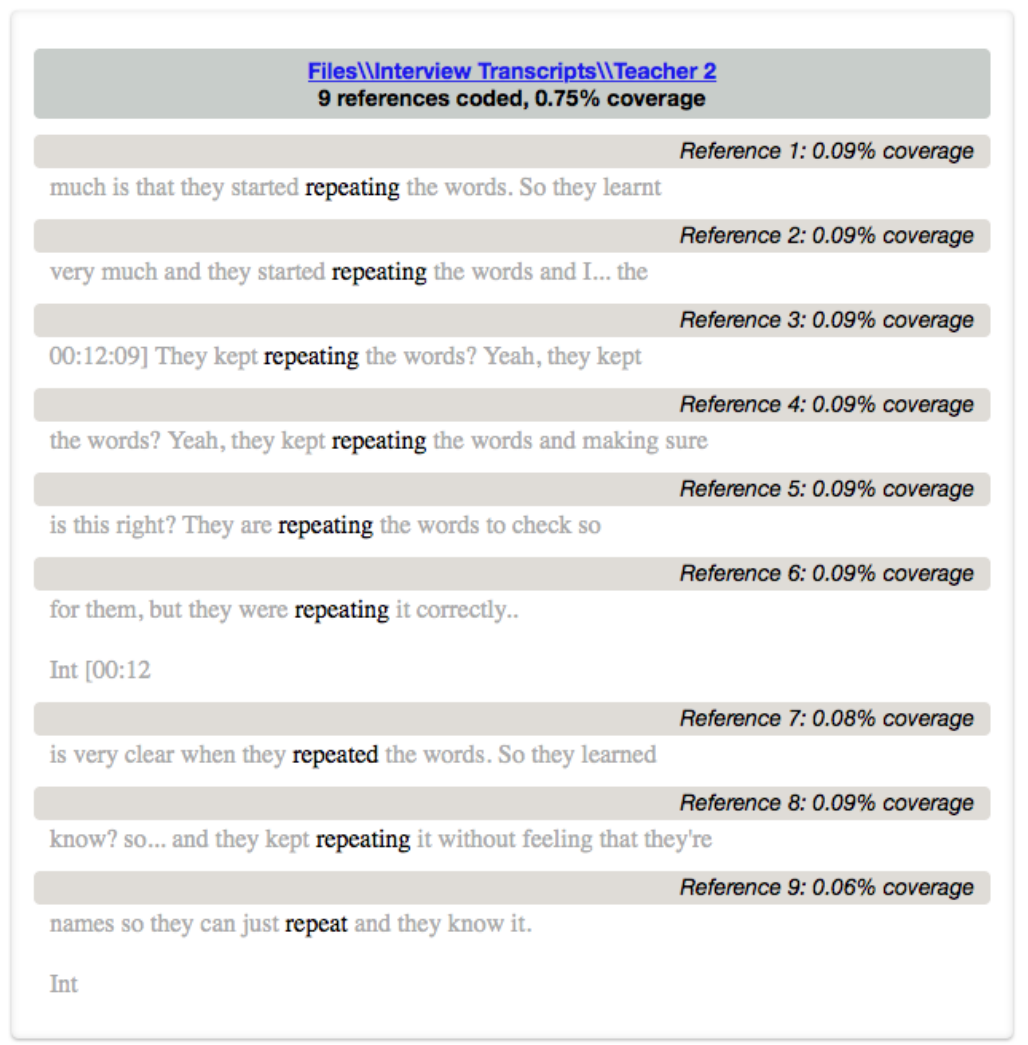

Fig. 8. NVivo word query displaying the references from Teacher 2 and the percentage of coverage

Pronunciation: A majority of the references to pronunciation were positive. All participants, bar teacher 1 , made reference to students learning the correct way to pronounce the names of elements of the map that were available through the application's audio features. Students who were unable to read words initially were prompted by teachers to raise the volume and were later recorded as having successfully read and pronounced previously unknown words (figure 9). Teachers perceived the effects of improvement in pronunciation to be '...very clear when they [students] repeated the words...' in the manner and accent that they were heard. 


\section{Files IVInterview Transcripts IITeacher 4}

1 reference coded, $1.52 \%$ coverage

Reference 1: $1.52 \%$ coverage

sometimes they couldn't read names of the countries at first. So I asked them to raise the volume and listen to the words. So they heard the word. So it was used for language purposes too

\section{Files IIInterview Transcripts IITeacher 6}

1 reference coded, $2.10 \%$ coverage

Reference $1: 2.10 \%$ coverage

They just kept saying the things with the same pronunciation. Even one student made fun of the other with the pronunciation the accent. Then I told him that that's the right pronunciation for the word. So they copied it. So we just kept saying the words as they are.

Fig. 9. Nvivo recorded reference coded within the theme of pronunciation

Grammar and translation: Despite having only one reference recorded for each, opportunities for grammar learning and translation were referred to. Teacher 1 discussed an intention to incorporate the learning of common nouns and proper nouns upon seeing the application, but later realized the capitalization of all words made that difficult. Teacher 7 saw further potential for language learning and expressed a desire to integrate the textual representations within the software into student language inquiry of prefixes and suffixes and the ethnology of the words learned (figures 10 and 11). Teacher 3 made reference to an improvement of the application, expressing a wish for a translation element in order to help students to compare newly learned words to with their own mother tongue.

FilesIUnterview TranscriptsIITeacher 1
3 references coded, $0.00 \%$ coverage
Reference 1: $0.00 \%$ coverage
It's really amazing and I got a couple of ideas in my mind other than the ones that we had
that we can include the language more into the thing.
References 2-3: $0.00 \%$ coverage
This was the first approach that I had when I first saw the application that I can use it with
the common nouns but then I found out that they're all capitalized. So we went out from the
common and proper to just mention some plants, mention some animals that live on this
continent. So we can add this specific part that these are plants - that live here. Those are
the common nouns. But what are the proper nouns, the names - special names for the plants
that lived on this continent, and then we can go further like the animals that live on those--
on those plants and this continent and then we can go to the habitats of those animals in this
continent and so on.

Fig. 10.Teacher 1: Nvivo snapshot of recorded reference coded within the theme of grammar. 
Reference 2: $9.85 \%$ coverage

We can add other buttons to... for example for talking about the language that... because this is the main concern that I really like to talk about... is that we can add buttons to show the past Maybe. The action that's going on in the picture that someone is walking and then we need to know that he's walking for the time being but how about the past? So in little icon at the side that shows black and white I can for example, so it shows what happened in the past when they click on the word and it shows the past of the verb that's that's one thing something else that we can use in changing the... adding suffixes and and to the to the main... the root words because this is one of the things that students would struggle with when it comes to adding prefixes or suffixes to the word. It's one of the struggling things that students will struggle with, so maybe we can have an icon that shows a little root at the side and then students will play with the possibilities how they can... with an action also that's happening in the in... in the video... that they can guess what er what they need to add to the root word is suffix or prefix. The last thing I was thinking about, because it was used to show the names of the animals and plants that grow on the continent, that we could add another thing that could talk about common and the proper nouns because all the nouns that we saw were capitalized.

Fig. 11.Teacher 7: Nvivo snapshot of recorded reference coded within the theme of grammar.

Despite the challenges faced by students, the participating teachers perceived and recorded multiple evidences of learning, in particular the enhancement of vocabulary.

The findings clearly point to the repetition of the AR application audio as the highest number of recorded references to vocabulary enhancement. However, what was not as clearly apparent was the positive role played by motivation, and engagement. Of the 8 participants, 6 participants contributed to the 16 references of perceived enhancement in motivation which aided engagement and learning.

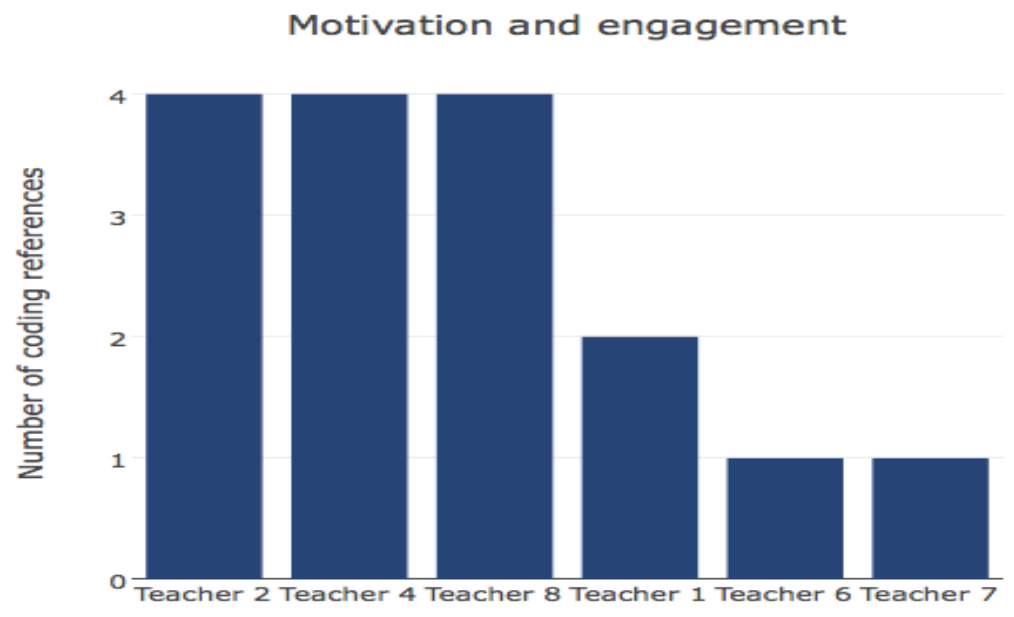

Fig. 12.Nvivo snapshot 6 participants contributed to the 16 references of perceived enhancement in motivation. 
The theme of motivation and engagement contained 3 coded sub-themes: play, fun, and relieves boredom. An typical example of the references can be found in the excerpt from Teacher 4 (figure 12 and 13) who implied that student motivation and engagement in the task resulted in less need for teacher supervision.

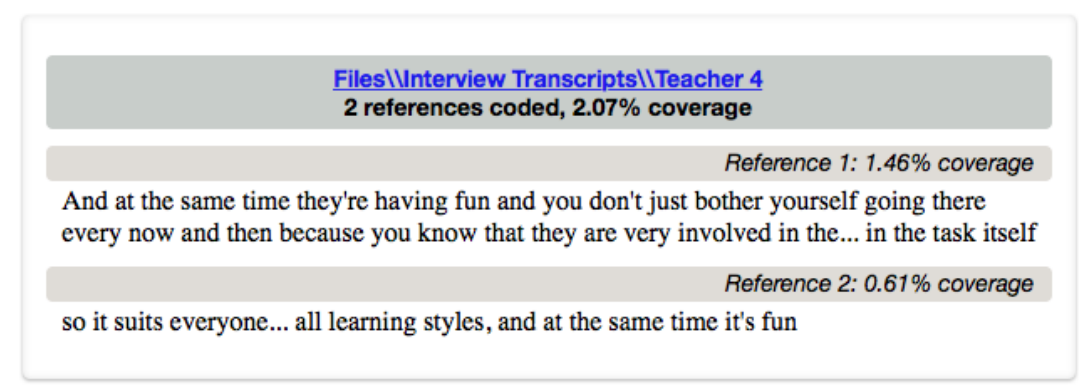

Fig. 13. Teacher 4 Reference to motivation and engagement.

Teacher 1 connected the motivation students had toward the technology to other centres of learning in the classroom, implying that students were so motivated to get to the technology centre that it improved their engagement in other centres of learning (figure 14).

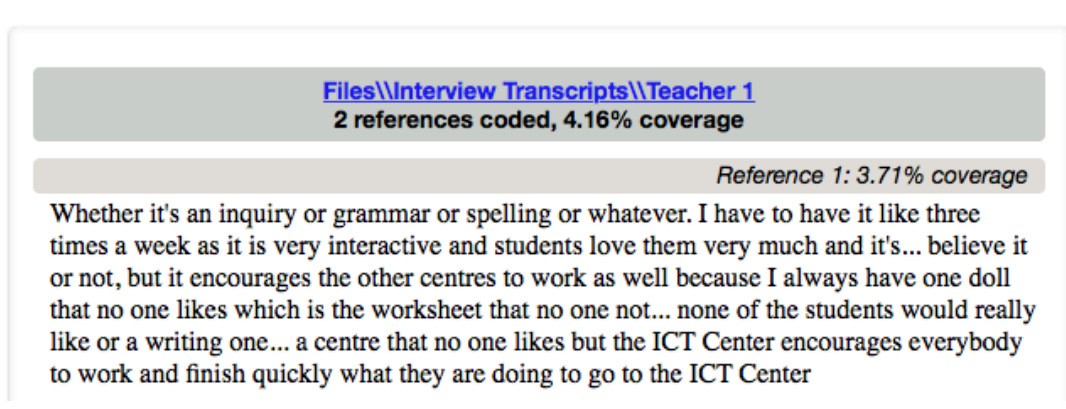

Fig. 14.Teacher 1 Reference to motivation and engagement.

Whilst references to these themes showed positive beliefs toward the role of motivation and engagement, there were also references to caution over how long the effect would last. Teacher 6 perceived that the effect the AR application had on student engagement and motivation may well reduce with continued use, but also implied that a different AR application may be the solution (figure 15). 


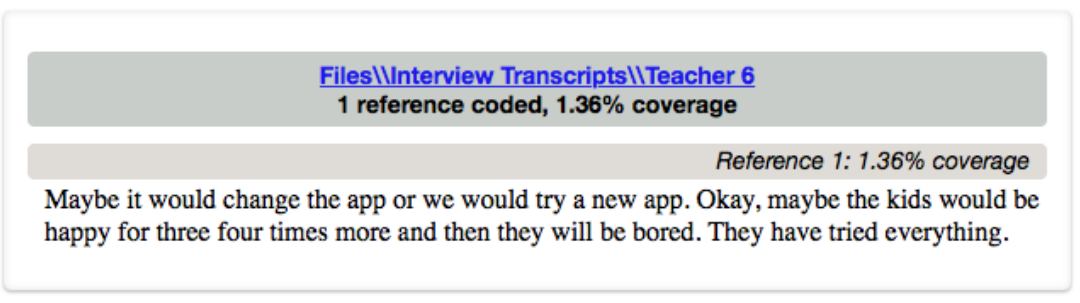

Fig. 15.Teacher 6 Reference to perceived limitations of student motivation over time.

\section{Conclusion}

$\mathrm{AR}$ is a valuable resource for learning in the PYP classroom. It motivates learners and results in positive levels of engagement. Predesigned applications are easy to use and require little training of teachers. However, it is a tool for learning and not the learning itself. The challenges are few, but significant. It requires familiarity with technology in order to be effectively for inquiry, and like all tools used in the PYP, it requires teachers to have the skill set needed to integrate the application's content into the conceptual units being learned. In order to be used for language learning it requires teachers to have that as an aim, and therefore the specific application used in the lessons needs to be selected carefully. Audio features have the potential to enhance vocabulary and in the case of native accents used, to improve pronunciation. But consideration must be made to the learning environment in which the application is used, as audio can prove hard to hear in an open classroom layout, which is often adopted in the PYP homeroom.

A larger, wider, and more diverse sample of PYP teachers observed through a mixed method methodology may give greater insight into the factors that could influence the findings of further studies: age, gender, levels of PYP experience, and grade levels taught.

\section{References}

[1] Alharbi, H. (2015). Improving students' English speaking proficiency in Saudi public schools. International Journal of Instruction. 8(1) pp. 105-116. Available at: https://www. scopus.com/record/display.uri?eid=2-s2.0-84921911263\&origin=inward\&txGid=32766c3 12cdb69a1a43d39586a362d4e

[2] Aldalalah, O.M., Ababneh, Z., Bawaneh, A. \& Alzubi, W. (2019). Effect of Augmented Reality and Simulation on the Achievement of Mathematics and Visual Thinking Among Students. International Journal of Emerging Technologies in Learning. 14(18) pp. 164-185. Available at: https://online-journals.org/index.php/i-jet/article/view/10748 https://doi.org/ 10.3991/ijet.v14i18.10748

[3] Furió, D., Juan, M., Seguí, I. \& Vivó, R. (2015). Mobile learning vs. traditional classroom lessons: a comparative study. Journal of Computer Assisted Learning. 31(3) pp.189-201. Available at: https://onlinelibrary.wiley.com/doi/abs/10.1111/jcal.12071 https://doi.org/1 $\underline{0.1111 / j \mathrm{jcal} .12071}$ 
[4] McIlwraith, H. \& Fortune, A. (2016). English language teachingnand learning in Egypt: an insight. London: British Council. Available at: https://www.teachingenglish.org.uk/sites/te acheng/files/pub_F239_English\%20Language\%20in\%20Egypt_FINAL\%20web.pdf

[5] British Council (2013). Perspectives on English in the Middle East and North Africa. London: British Council. Available at: https://englishagenda.britishcouncil.org/continuingprofessional-development/cpd-researchers/perspectives-english-middle-east-and-north-afri ca https://doi.org/10.1093/ww/9780199540884.013.u288372

[6] Alqahtani, M. (2015). The importance of vocabulary in language learning and how to be taught. International Journal of Teaching and Education. 111(3) pp.21-34. Available at: $\underline{\mathrm{t}}$ tps://www.iises.net/international-journal-of-teaching-education/publication-detail-213 http s://doi.org/10.20472/te.2015.3.3.002

[7] Hulstijn, J. (1992). Retention of Inferred and Given Word Meanings: Experiments in Incidental Vocabulary Learning. In: Arnaud P. \& Béjoint, H. (eds). Vocabulary and Applied Linguistics. Palgrave Macmillan: London. https://doi.org/10.1007/978-1-349-123 $\underline{96-4 \_11}$

[8] Solano, L., Cabrera, P., Ulehlova, E. \& Espinoza, V. (2017). Exploring the use of educational technology in EFL teaching: A case study of primary education in the south region of Ecuador. Teaching English with Technology. 17(2) pp.77-86. Available at: https ://eric.ed.gov/?id=EJ1140683

[9] Sánchez-Vera, M., León-Urrutia, M. \& Davis, H. (2015). Challenges in the Creation, Development and Implementation of MOOCs: Web Science Course at the University of Southampton. Comunicar. 22(44) pp.37-44. Available at: https://eprints.soton.ac.uk/37406 8/ https://doi.org/10.3916/c44-2015-04

[10] Tezer, M. Yıldız, E.P., Masalimova, A.R., Fatkhutdinova, A.M., Zheltukhina, M.R., Khairullina, E.R. (2019). Trends of Augmented Reality Applications and Research throughout the World: Meta-Analysis of Theses, Articles and Papers between 2001-2019 Years. International Journal of Emerging Technologies in Learning. 14(22), 154-174. Available at: https://online-journals.org/index.php/i-jet/article/view/11768 https://doi.org/ 10.3991/ijet.v14i22.11768

[11] IBO (2017). The Primary Years Programme as a model of transdisciplinary learning. Cardiff, Wales: International Baccalaureate Organisation. Available at: http://www.foshay lc.org/ourpages/auto/2013/1/17/53115145/The\%20Primary\%20Years\%20Programme $\% 20$ as\%20a\%20Mode1\%20of\%20TL.pdf.

[12] Mancebo May, P., Schmidt, W. \& Vlachopoulos, D. (2020). The use of augmented reality (AR) in museum education: a systematic literature review. 14th annual International Technology, Education and Development Conference. Valencia. https://doi.org/10.21125/ inted.2020.0917

[13] Yang, P., Schmidt, W. \& Vlachopoulos, D. (2020). Virtual Reality (VR) in museum education: a systematic literature review. 14th annual International Technology, Education and Development Conference. Valencia. https://doi.org/10.21125/inted.2020.1218

[14] Okaro, I. \& Vlachopoulos, D. (2020). Exploring the use of mixed reality (MR) in museum education: a systematic literature review. 14th annual International Technology, Education and Development Conference. Valencia. https://doi.org/10.21125/inted.2020.1830

[15] Lai, C. \& Hwang, G. (2016). A self-regulated flipped classroom approach to improving students' learning performance in a mathematics course. Computers \& Education. 100(5) pp.126-140. Available at: https://www.sciencedirect.com/science/article/abs/pii/S0360131 516301166 https://doi.org/10.1016/j.compedu.2016.05.006

[16] Azuma, R. (1997). A Survey of Augmented Reality. Presence. 6(4) pp.355-385. Available at: https://www.cs.unc.edu/ azuma/ARpresence.pdf 
[17] Dunleavy M. \& Dede C. (2014). Augmented Reality Teaching and Learning. In: Spector, J., Merrill, M., Elen, J. \& Bishop, M. (eds). Handbook of Research on Educational Communications and Technology. New York, NY: Springer. https://doi.org/10.1007/978-1 -4614-3185-5_59

[18] Shelton, B. \& Hedley, N. (2002). Using augmented reality for teaching Earth-Sun relationships to undergraduate geography students. Presented at: IEEE International Augmented Reality Toolkit Workshop, Darmstadt, Germany. https://doi.org/10.1109/art.20 02.1106948

[19] Kerawalla, L., Luckin, R., Seljflot, S. \& Woolard, A. (2006). "Making it real”: Exploring the potential of augmented reality for teaching primary school science. Virtual Reality. 10(3-4) pp.163-174. Available at: https://link.springer.com/article/10.1007/s10055-006-00 36-4 https://doi.org/10.1007/s10055-006-0036-4

[20] Billinghurst, M., Kato, H., \& Poupyrev, I. (2001). The MagicBook: A transitional AR interface. Computers and Graphics. 25(5) pp.745-753. Available at: http://hitl.washington. edu/people/tfurness/courses/inde543/READINGS-03/BILLINGHURST/MagicBook.pdf $\underline{\text { ht }}$ tps://doi.org/10.1016/s0097-8493(01)00117-0

[21] Santos, M., Lübke, A., Taketomi, T., Yamamoto, G., Rodrigo, M., Sandor, C., \& Kato, H. (2016). Augmented reality as multimedia: the case for situated vocabulary learning. Research and Practice in Technology Enhanced Learning. 11(1). Available at: https://link. springer.com/article/10.1186/s41039-016-0028-2 https://doi.org/10.1186/s41039-016-0028 $\underline{-2}$

[22] Lester, J., Lochmiller, C., Williamson, S. \& Germain, J. (2014). A Mixed Method Case Study of International Baccalaureate Primary Year Programmes in Four Colombian Schools. Indiana: Indiana University, Center for Evaluation \& Education Policy.

[23] Vooren, C., Lai, C., Ledger, S., Villaverde, A. \& Steffen, V. (2013). Additional Language Teaching and Learning in International Baccalaureate Primary Years Program Schools. The Hague, Netherlands: International Baccalaureate Organisation. Available at: https:// www.ibo.org/globalassets/publications/ib-research/ib-summary-pypadditionallanguageeng. pdf

[24] Zhang, J. (2013). Decreasing Cognitive Load for Learners: Strategy of Web-Based Foreign Language Learning. International Education Studies. 6(4) pp.134-139. Available at: http:// www.ccsenet.org/journal/index.php/ies/article/view/24311 https://doi.org/10.5539/ies.v6n4 p134

[25] Cheng, K. (2016). Reading an augmented reality book: An exploration of learners' cognitive load, motivation, and attitudes. Australasian Journal of Educational Technology. 33(4) pp.53-69. Available at: https://ajet.org.au/index.php/AJET/article/view/2820 https:// doi.org/10.14742/ajet.2820

[26] Chu, H. (2014). Potential Negative Effects of Mobile Learning on Students' Learning Achievement and Cognitive Load- A Format Assessment Perspective. Educational Technology and Society. 17(1) pp. 332-344. Available at: https://www.jstor.org/stable/jed uctechsoci.17.1.332?seq=1

[27] Brown, M., Costello, E., Donlon, E. \& Nic Giolla-Mhichil, M. (2015). A strategic response to MOOCs: How one European university is approaching the challenge. The International Review of Research in Open and Distributed Learning. 16(6) pp.98-115. Available at: http ://www.irrodl.org/index.php/irrodl/article/view/2151 https://doi.org/10.19173/irrodl.v16i6. $\underline{2151}$

[28] Solak, E. \& Cakir, R. (2015). Investigating the Role of Augmented Reality Technology in the Language Classroom. Croatian Journal of Education. 18(4) pp. 1067-1084. Available at: https://pdfs.semanticscholar.org/52ca/9ac33c192a648f894b4fca89ee942b3968fb.pdf 
[29] Prensky, M. (2004). The emerging online life of the digital native. Available at: http://www.bu.edu/ssw/files/pdf/Prensky-The_Emerging_Online_Life_of_the_Digital_Na tive-033.pdf (Accessed: 14/1/20).

[30] Ozdamli, F. \& Hursen, C. (2017). An Emerging Technology: Augmented Reality to Promote Learning. International Journal of Emerging Technologies in Learning. 12(11) pp.121-137. Available at: https://online-journals.org/index.php/i-jet/article/view/7354 https ://doi.org/10.3991/ijet.v12i11.7354

[31] Cabero, J. \& Barroso, J. (2016). The educational possibilities of Augmented Reality. Journal of New Approaches in Educational Research. 6(1) pp.44-50. Available at: https:// naerjournal.ua.es/article/view/v5n1-7 https://doi.org/10.7821/naer.2016.1.140

[32] Li, S., Chen, Y., Whittinghill, D. \& Vorvoreanu, M. (2014). A Pilot Study Exploring Augmented Reality to Increase Motivation of Chinese College Students Learning English. ASEE Annual Conference. Indianapolis, IN: ASEE.

[33] Heath, M. (2017). Teacher-Initiated One-to-One Technology Initiatives: How Teacher Self-Efficacy and Beliefs Help Overcome Barrier Thresholds to Implementation. Computers in the Schools. 34(1-2) pp.88-106. Available at: https://www.tandfonline.com/ doi/abs/10.1080/07380569.2017.1305879? journalCode=wcis20 https://doi.org/10.1080/07 $\underline{380569.2017 .1305879}$

[34] Mundy, M., Kupczynski, L. \& Kee, R. (2012). Teacher's Perceptions of Technology Use in the Schools. SAGE Open. 2(1) pp. 2-8. Available at: https://journals.sagepub.com/doi/ full/10.1177/2158244012440813 https://doi.org/10.1177/2158244012440813

[35] Smeets, E. (2005). Does ICT contribute to powerful learning environments in primary education?. Computers \& Education. 44(3) pp. 343-355. Available at: https://www.science direct.com/science/article/abs/pii/S0360131504000569 https://doi.org/10.1016/j.compedu. 2004.04.003

[36] Niederhauser, D. \& Stoddart, T. (2001). Teachers' instructional perspectives and use of educational software. Teaching and Teacher Education. 17(1) pp.15-31. Available at: https ://www.sciencedirect.com/science/article/abs/pii/S0742051X00000366 https://doi.org/10.1 016/s0742-051x(00)00036-6

[37] Tondeur, J., van Braak, J., Ertmer, P. \& Ottenbreit-Leftwich, A. (2017). Understanding the relationship between teachers' pedagogical beliefs and technology use in education: a systematic review of qualitative evidence. Educational Technology Research and Development. 65(3) pp.555-575. Available at: https://link.springer.com/article/10.1007/s1 1423-016-9481-2 https://doi.org/10.1007/s11423-016-9481-2

[38] Benbasat, I., Goldstein, D. \& Mead, M. (1987). The Case Research Strategy in Studies of Information Systems. MIS Quarterly. 11(3), pp. 369-386. Available at: https://www.jstor. org/stable/248684?seq=1 https://doi.org/10.2307/248684

[39] Punch, K. (2009) Introduction to Research Methods in Education. London: Sage Publications.

\section{$7 \quad$ Authors}

Ahmed (Sam) Welbeck serves as an international school principal. He has earned degrees from Queen Mary and Roehampton Universities of London and has conducted research earning him a Master's Degree in Education. He is currently a doctoral student in the Department of Educational Leadership at Acacia University, USA. Sam is an established public speaker, and is regularly invited to speak on the 
importance of learner centered pedagogy, as well as his specialisation in educational technologies, particularly augmented reality.

Dimitrios Vlachopoulos is program manager of the track "EdTech for Social Change" at Amsterdam University of Applied Sciences. Since 2005, he has been working as faculty member in different universities in the Netherlands, the UK, the USA, Spain and Cyprus. He is a committed lifelong learner with a PhD in distance education and instructional technology and 5 MA degrees in education and social sciences. He is a Senior Fellow of the Higher Education Academy (SFHEA) and Fellow of the Royal Society of Arts (FRSA). Dimitrios has more than 80 publications in peer-reviewed journals, books and international conferences and has participated in more than $15 \mathrm{EU}$ projects related to education and ICT.

Article submitted 2020-02-01. Resubmitted 2020-03-22. Final acceptance 2020-03-22. Final version published as submitted by the authors. 